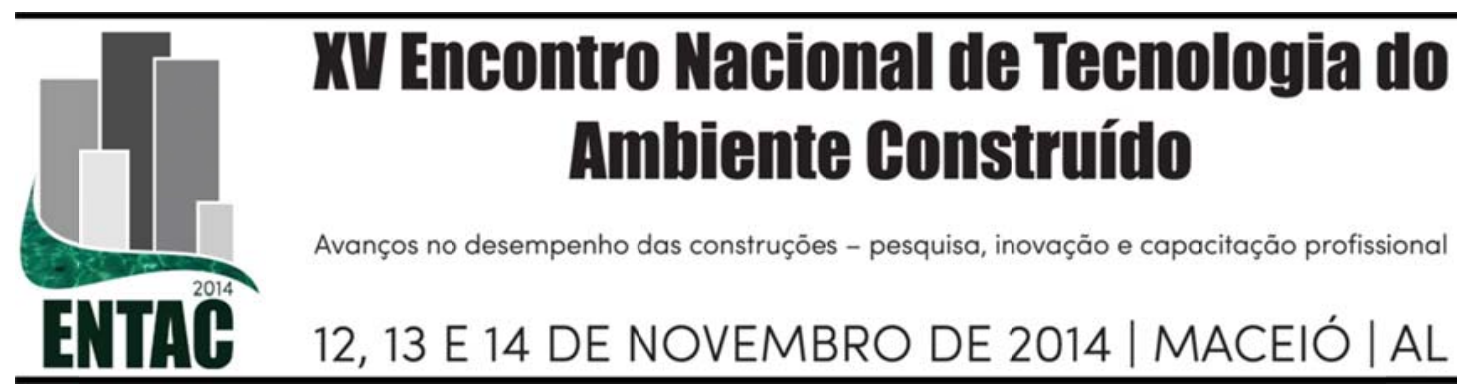

\title{
RESILIÊNCIA ÀS MUDANÇAS CLIMÁTICAS: CONFORTO TÉRMICO DE IDOSOS EM UNIDADES RESIDENCIAIS
}

\author{
SATO, Andre Eiji (1); GONÇALVES, Fabio Luiz Teixeira (2); \\ MONTEIRO, Leonardo Marques (3)
}

(1) FAUUSP, e-mail: andre.e.sato@gmail.com; (2) IAGUSP, e-mail: fgoncalv@model.iag.usp.br; (3) FAUUSP, e-mail: leo4mm@gmail.com

\begin{abstract}
RESUMO
Este artigo é fundamentado na comparação cruzada entre dados levantados em campo com dados obtidos a partir da literatura internacional na área de conforto térmico em espaços internos urbanos. O objetivo deste trabalho é a avaliação de desempenho térmico de unidades residenciais de idosos da Região Metropolitana de São Paulo no cenário climático atual, tendo em vista as condições de conforto térmico frente às mudanças climáticas previstas. O método utilizado é empírico-induttivo, por meio de levantamentos de campo e teórico-dedutivo por meio de comparações entre os resultados obtidos em campo com os obtidos pelos índices de conforto térmico (ASHRAE-55, 2010). Ao final dos estudos, verificou-se que a percepção do idoso perante a própria realidade térmica difere daquela tida a partir de modelos de conforto térmico adaptativo. Há certa tendência dos idosos não identifícarem situações de desconforto térmico por calor, e, portanto, se encontram mais vulneráveis ao aumento de temperatura. Assim, cabe à edificação oferecer condições adequadas de conforto térmico baseadas em estratégias de adaptação aos parâmetros climáticos futuros, bem como de mitigação do consumo energético. Apesar dos avanços na área científica brasileira de conforto térmico, é possível notar que não houve abordagens relativas à vulnerabilidade da população idosa. Dessa maneira, este trabalho serve como ponto de partida para que outras pesquisas possam explorar mais o tema e assim, contribuir para a segurança dessa crescente parcela da sociedade diante das mudanças climáticas previstas.
\end{abstract}

Palavras-chave: Conforto térmico, mudanças climáticas, vulnerabilidade da população idosa.

\begin{abstract}
This paper is based on a cross-comparison between the data collected in the field with the data from the international literature in the area of thermal comfort in urban domestic spaces. The aim of this research is the evaluation of thermal performance of elderly residential units in the Metropolitan Region of Sao Paulo in the current climatic scenario, having in mind the thermal comfort conditions in the forecasted climatic scenario. The method is empirical-inductive through field surveys and theoretical-deductive by comparisons between the results obtained in the field with those obtained by means of thermal comfort indices (ASHRAE-55, 2010). It was verified at the end of this study that the elderly perception of their thermal reality differs from that obtained by the adaptive thermal comfort. The elderly shows a tendency to not identify situations of thermal discomfort caused by heat and thus, they become more vulnerable to the temperature increase. So, it is up to the building to provide adequate conditions of thermal comfort based on strategies of adaptation to the future climatic parameters and also strategies of mitigation of energy consumption. Despite advances in the Brazilian scientific area of thermal comfort, it is possible to notice that there were no approaches to vulnerability of elderly population. Thus, this paper serves as a starting point for further researches to explore even more the topic and in this way, to contribute to the safety of this growing portion of the society facing the climate changes predicted.
\end{abstract}

Keywords: Thermal comfort, climate changes, vulnerability of the elder population. 


\section{INTRODUÇÃO E FUNDAMENTAÇÃO TEÓRICA}

Gastos energéticos ocorrem em todas as fases do ciclo de vida de uma edificação. Na fase de operação, porém, ocorre a maior parte do consumo (UNEP, 2007), principalmente os gastos energéticos decorrentes das funções de resfriamento e aquecimento dos ambientes. As mudanças climáticas podem ocasionar alterações no desempenho dos edifícios construídos nos padrões atuais e/ou um aumento no uso de energia, especialmente para resfriamento ativo no caso do Brasil. Desse modo, ou o conforto humano estará comprometido, ou haverá aumento na demanda energética. Daí a relevância de adaptar os edifícios aos parâmetros climáticos previstos e mitigar o consumo energético fornecendo ao mesmo tempo condições adequadas de conforto ambiental.

Esse trabalho de adaptação e mitigação se torna essencial, principalmente nas áreas urbanizadas e nos edifícios já que dois grandes fatores são influenciadores nesse processo: o ritmo acelerado da urbanização aumenta a vulnerabilidade dos habitantes aos impactos das mudanças climáticas e megacidades, como São Paulo, funcionam como amplificadores dessas alterações. Independentemente das alterações climáticas globais, as cidades tendem a ter temperaturas do ar e de superfície mais altas do que os ambientes rurais (UN-HABITAT, 2011). É por isso que esta pesquisa se propôs a estudar residências habitacionais apenas em ambiente urbano, neste caso a Região Metropolitana de São Paulo (RMSP). Projeções de mudanças na precipitação e temperatura médias anuais até 2100 indicam, nos cenários de altas emissões globais de gases de efeito estufa, um aumento de $2^{\circ} \mathrm{C}$ a $4^{\circ} \mathrm{C}$ e resultarão em um aumento no número de dias frios e de noites quentes na RMSP. No que se refere à precipitação, caso a região metropolitana siga seu padrão de expansão e de aumento da temperatura média, o esperado é que a quantidade de chuvas seja o dobro da atual, o que poderá aumentar potencialmente os riscos de enchentes, inundações e deslizamentos de terras (NOBRE et al, 2010).

Como as pessoas passam a maior parte de seu tempo no interior de edificações, uma de suas funções vitais é prover condições adequadas de conforto ambiental, em especial de conforto térmico, dados os cenários climáticos previstos. Pode-se definir conforto térmico como a condição mental que expressa satisfação com o ambiente térmico, sendo assim avaliada por meio da subjetividade. (ASHRAE, 2010).

Assim, os setores da construção civil, da arquitetura e do urbanismo podem prestar grandes contribuições tanto para adaptação quanto para mitigação. Em relação aos fatores climáticos, a arquitetura pode responder às exigências de conforto térmico de três formas: com condicionamento passivo, dentro de certos limites; condicionamento ativo por $100 \%$ do tempo de operação; ou condicionamento em modo misto de operação. Dependendo dos cenários climáticos futuros, é necessário projetar os edifícios para que os mesmos mantenham a sua operação inclusive em situações de racionamento energético, o que dificulta a opção pelo sistema de operação exclusivamente ativo. Outro importante meio para promover maior independência de consumo energético é a adoção de índices de conforto adaptativo (JOHN et al., 2001). Os índices foram estabelecidos a partir das variáveis térmicas envolvidas na identificação das condições de conforto. Após diversos estudos no cenário mundial, percebeu-se que diferentes agrupamentos de variáveis podem gerar condições finais que resultem numa resposta de conforto térmico semelhantes entre si, determinando-se assim os índices de conforto térmico (FROTA; SCHIFFER, 2003). Estes podem relacionar duas ou comumente mais variáveis entre as descritas a seguir: ambientais (temperatura, umidade e velocidade do 
ar e radiação térmica), individuais (vestimentas e atividade física) e subjetivas (percepção ou preferência de sensações térmicas).

Para esta pesquisa foram considerados dois índices de conforto térmico, o primeiro deles desenvolvido seguindo os padrões normativos internacionais (ASHRAE, 2010); e o segundo criado especificamente para a RMSP, desenvolvido por um dos autores deste artigo (MONTEIRO, 2008). O índice de conforto térmico presente na ASHRAE-55 (2010) trabalha com seis variáveis primárias: taxa metabólica, vestimenta, temperatura do ar, temperatura radiante, velocidade do ar e umidade. Esse índice é baseado no chamado modelo adaptativo de conforto térmico. Tem-se por definição de modelo adaptativo segundo a mesma norma, uma das primeiras a considerá-lo, como um modelo que relaciona uma temperatura interna ou um intervalo de temperaturas aceitáveis com parâmetros externos meteorológicos ou climatológicos. Assim, para estabelecer uma situação de conforto térmico, as temperaturas internas devem variar conforme as temperaturas externas do entorno do edifício, o qual deve ser ventilado naturalmente. Isso é explicado pelo fato de que o ser humano espera condições e sensações térmicas diferentes nos períodos de verão e de inverno e não apenas uma temperatura adequada uniforme que valha para o ano inteiro. É um modelo vantajoso, já que quando a diferença entre as temperaturas interna e externa é reduzida, há consequentemente, uma redução no uso de energia para estabelecer uma situação de conforto térmico. (NICOL; HUMPHREYS; ROAF, 2012)

Um indivíduo que visa o ambiente térmico deve ser capaz de determinar os valores de diversos índices de conforto, que serão responsáveis por identificar as situações climáticas aceitáveis ou o nível de estresse térmico do usuário. No entanto, torna-se necessário uma complementação dos valores propostos em uma abordagem inicial indutiva. Ela se dá por meio de uma determinação direta da experiência subjetiva do usuário em relação ao próprio ambiente que resulta numa opinião pessoal, um meio em que possa expor seu julgamento e expressão diante do conforto térmico. (ISO, 1995). Em se tratando de quantificação subjetiva, Nicol (2012) explicita que a criação de um questionário em campo é essencial. Segundo ele, a escala de sensação térmica é tradicionalmente utilizada como meio para se obter as variáveis subjetivas. $\mathrm{O}$ usuário em questão fornece a sua própria percepção e avaliação de sensação térmica em uma escala que utiliza como critérios um ponto central neutro e escalas de intensidades positivas e negativas. Esses critérios estão contidos na norma internacional ISO 10551 (1995), que propõe um questionário de cinco perguntas padrão englobando temáticas de percepção, avaliação e preferência de conforto térmico. Foi a partir desta norma que os questionários dessa presente pesquisa foram elaborados.

Assim, diante do cenário climático atual e futuro, um dos maiores desafios para a espécie humana é a adaptação ao ambiente em que vive marcado principalmente por temperaturas e amplitudes mais elevadas. Isso se encontra diretamente relacionado com a saúde humana, já que essas mudanças de temperatura influenciam na capacidade do indivíduo em manter a sua temperatura interna constante a aproximadamente $37^{\circ} \mathrm{C}$. É justamente por este fato, da temperatura externa variar mais que a temperatura corporal interna, que o fenômeno denominado termorregulação (FROTA; SCHIFFER, 2003) é realizado a partir de processos metabólicos. Nele também influenciam mecanismos voluntários de adaptação comportamental como vestimentas, alimentação, migração, atividade desempenhada, entre outros (JENDRITZKY; DE DEAR, 2009).

No entanto, nem todo ser humano consegue responder às variações de temperatura de forma adequada e eficiente. Existem grupos mais suscetíveis aos efeitos dessas mudanças climáticas. Este é o caso da população de idosos, a qual representa uma 
parcela que tem aumentado sua participação no montante total da população do país. Dados da RMSP revelam que a população com idade acima de 60 anos na metrópole corresponde a $11,3 \%$ da população total (IBGE, 2010). A tendência é de que esta progressão continue nas próximas décadas. Os idosos são mais suscetíveis às sobrecargas que o clima impõe por motivos fisiológicos e comportamentais. Estes indivíduos, com 60 anos ou mais, têm um declínio na sua capacidade termorregulatória, mesmo quando saudáveis (AUERBACH, 2007; UN-HABITAT, 2011). Sendo assim, o aumento na frequência de extremos de temperatura, indicadas nas projeções climáticas, poderá aumentar seus efeitos adversos principalmente entre a população geriátrica. Dessa maneira, é por este motivo que a pesquisa foca nesse tipo de grupo.

Assim, ante esse enfoque, é por tal razão que esta pesquisa se propôs a avaliar o conforto térmico de idosos dentro de suas próprias unidades residenciais no cenário climático atual. Essa avaliação se deu segundo uma comparação cruzada entre as condições de conforto térmico estabelecidas conforme o modelo adaptativo apresentado na ASHRAE-55 (2010) e as variáveis subjetivas obtidas por meio dos questionários, estes baseados na obra de MONTEIRO e ALUCCI (2010).

\section{OBJETO E OBJETIVO}

O objeto desta pesquisa é o desempenho térmico de edifícios residenciais na Região Metropolitana de São Paulo no cenário climático atual, face às mudanças climáticas previstas para as próximas décadas e à maior vulnerabilidade de alguns grupos populacionais como, por exemplo, de idosos. O objetivo é a avaliação de desempenho térmico de unidades residenciais de idosos no cenário climático atual, tendo em foco as condições de conforto térmico diante das mudanças climáticas previstas (conforme cenários do International Pannel on Climate Change - IPCC), que indicam temperaturas e amplitudes térmicas mais altas.

\section{MÉTODOS}

A metodologia desta pesquisa seguiu primeiramente de forma empírico-indutiva por meio de levantamentos em campo e posteriormente de forma teórico-dedutiva por meio de comparações dos dados empíricos com os dados teóricos obtidos segundo a norma internacional ASHRAE-55 (2010).

Os levantamentos empíricos se deram a partir da amostra da pesquisa de seis residências de voluntários idosos. As residências se encontram em bairros distintos, mas ainda dentro da Região Metropolitana de São Paulo, mais especificamente, dentro do município de São Paulo. Para preservação sigilosa da identificação do voluntário assim como do endereço exato da residência, a cada integrante da amostra foi atribuído o nome do respectivo bairro: Freguesia do Ó, Cerqueira César, Vila Ida, Brooklin Novo, Aclimação e Rio Pequeno.

Os levantamentos foram obtidos respectivamente em dias típicos de inverno e de verão por abrangerem situações climáticas distintas e quase opostas. Consistiram na coleta de dados de variáveis microclimáticas assim como na aplicação de questionários. É importante salientar que no primeiro período (no de inverno) ocorreram os levantamentos dimensionais, construtivos e fotográficos das residências selecionadas para a amostra.

Essa coleta de dados se deu por meio de um aparelho de medição chamado de confortímetro. De fabricação nacional, esse aparelho coleta simultaneamente dados de quatro variáveis microclimáticas: temperatura do ar, temperatura de globo, umidade 
relativa e velocidade do ar. Antes da sua utilização efetiva nas residências, foram realizados diversos testes com o intuito de ajustá-los comparativamente com outros aparelhos de laboratório e calibrá-los para uma maior exatidão. Assim, foram designados dois aparelhos por residência, sendo escolhidos como ambientes de estudo a sala de estar e o dormitório. Essa escolha se deu pelo fato de serem ambientes de maior permanência e dessa maneira, os que mais influem na saúde e na percepção térmica dos usuários. Cada aparelho foi instalado sobre um tripé em local que não atrapalhasse quaisquer atividades habituais dos habitantes da residência. Para tanto, houve participação e consentimento do responsável pela moradia. Os confortímetros foram programados para gravar dados das quatro variáveis, de minuto a minuto, durante todo o período de coleta.

\section{Figura 1 - Confortímetro e sua utilização}
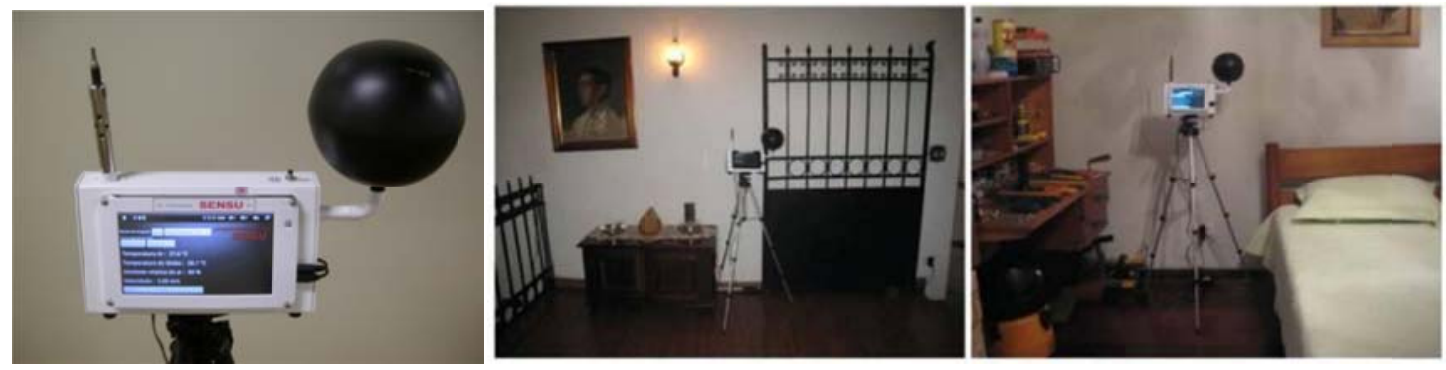

Fonte: autoria própria (2013)

Os questionários da presente pesquisa tiveram por objetivo coletar a percepção e preferência de sensação e conforto térmico do voluntário idoso em um ambiente fechado e habitual para o mesmo. Após diversos testes, sua aplicação definitiva se deu no momento da retirada dos equipamentos de cada período (de inverno e de verão). Tomou-se por base a norma ISO10551 Ergonomics of the thermal environment Assessment of the influence of the thermal environment using subjective judgement scales, publicada em 1995. O questionário formulado era dividido em duas seções: a primeira delas tinha por objetivo identificar visualmente informações acerca das variáveis individuais (resistência térmica da vestimenta - CLO e taxa de metabolismo MET). Assim, dados como tipo e coloração de roupa e atividade exercida no momento da aplicação foram visualmente estimados. Já a segunda tratava das variáveis subjetivas em si. Para tanto foram criadas escalas como meio de aferir a avaliação e a qualificação do entrevistado perante o ambiente térmico e também o acústico. Este último se inclui no questionário como meio de verificar a existência ou não de estresse acústico do entrevistado, pois esse fato pode influenciar negativamente as demais respostas. Em se tratando de influência, foram desenvolvidas outras questões que possivelmente permitissem a sua identificação. Dados como local de origem do entrevistado e tempo de residência na Grande São Paulo foram obtidos, já que o histórico térmico-climático recente possui grande relevância. Assim como a verificação de alterações nas atividades metabólicas, como por exemplo, a alimentação, a ingestão de bebida alcoólica e medicação.

\subsection{Tratamento dos dados coletados empiricamente}

Após a coleta dos dados obtidos a partir dos levantamentos empíricos, deu-se o tratamento dos mesmos para que uma análise comparativa posterior pudesse ser realizada. 
Em cada um dos dois períodos em que ocorreu o levantamento dos dados microclimáticos, fez-se uma seleção de um intervalo de tempo o qual se caracterizou por apresentar medições simultâneas e coerentes dentre todos os confortímetros instalados. Em alguns equipamentos foram detectados problemas de gravação sendo que em alguns casos os mesmos foram reinicializados e as medições retomadas. No entanto, em outros não houve o mesmo sucesso, apresentando erros que não puderam ser contornados.

Os dados referentes às medições de inverno compreenderam um intervalo de tempo total de seis dias e os referentes às medições de verão compreenderam dez dias. Pela grande quantidade de dados obtidos, fez-se uma média dos dados obtidos minuto a minuto a cada hora. Entende-se que esse processo forneceria uma leitura mais próxima da realidade.

Para a análise das condições de conforto térmico de cada residência, utilizou-se o modelo apresentado na norma ASHRAE-55 (2010) o qual relaciona temperatura operativa interna com temperatura média mensal externa. A partir dessa relação foi possível obter a porcentagem teórica de usuários satisfeitos mediante a condição térmica interna. Dessa maneira, a partir das medições realizadas nos períodos de inverno e verão, obtiveram-se as condições de conforto em cada residência. Para tanto foi necessário a conversão das variáveis microclimáticas em temperatura operativa conforme a equação abaixo:

$$
\mathrm{T}_{\mathrm{o}}=\frac{\mathrm{h}_{\mathrm{r}} \cdot \mathrm{T}_{\mathrm{rm}}+\mathrm{h}_{\mathrm{c}} \cdot \mathrm{T}_{\mathrm{ar}}}{\mathrm{h}_{\mathrm{r}}+\mathrm{h}_{\mathrm{c}}}
$$

onde, $\mathrm{T}_{\mathrm{o}}=$ Temperatura operativa $\left[{ }^{\circ} \mathrm{C}\right]$;

$\mathrm{h}_{\mathrm{r}} \quad=$ Coeficiente de transferência de calor radiativo linear $\left[\mathrm{W} / \mathrm{m}^{2}{ }^{\circ} \mathrm{C}\right]$;

$\mathrm{T}_{\mathrm{rm}}=$ Temperatura radiante média $\left[{ }^{\circ} \mathrm{C}\right] ;$

$\mathrm{h}_{\mathrm{c}} \quad=$ Coeficiente de transferência de calor convectivo $\left[\mathrm{W} / \mathrm{m}^{2}{ }^{\circ} \mathrm{C}\right]$;

$\mathrm{T}_{\mathrm{ar}}=$ Temperatura do ar $\left[{ }^{\circ} \mathrm{C}\right]$.

No caso da presente pesquisa foi utilizado o equacionamento como consta na obra de Nicol; Humphreys; Roaf (2012), adotando-se o valor de $h_{r}$ de $4,7 \mathrm{~W} / \mathrm{m}^{2}{ }^{\circ} \mathrm{C}$, para roupas usuais e o valor de $h_{c}$ de $3,1 \mathrm{~W} / \mathrm{m}^{2}{ }^{\circ} \mathrm{C}$, para velocidades do ar inferiores a $2 \mathrm{~m} / \mathrm{s}$ e para pessoas em pé. Para o cálculo da temperatura média mensal externa tomou-se por base os dados horários obtidos pela estação meteorológica externa do Instituto de Astronomia, Geofísica e Ciências Atmosféricas da Universidade de São Paulo (IAGUSP) referentes ao ano de 2013. É importante salientar que para cada valor horário da temperatura média mensal externa utilizado para estabelecer as condições de conforto térmico, fez-se uma média entre os valores da mesma variável dos últimos trinta dias. Tal razão se dá pelo aspecto da influência do histórico recente das condições climáticas vividas pelo usuário.

\section{RESULTADOS E DISCUSSÃO}

Com os dados tratados adequadamente, partiu-se então para a análise de caráter comparativo entre os dados reais do ambiente, os quais estabeleceram as condições de conforto térmico segundo o modelo adaptativo da norma ASHRAE-55 (2010); com as respostas subjetivas dadas pela percepção da sensação e do conforto térmico pelo voluntário idoso.

Analisando primeiramente as condições de conforto térmico segundo o modelo adaptativo, apesar de ser possível distinguir claramente as duas condições obtidas (para 
inverno e verão), é possível notar que não há uma diferença muito grande entre as temperaturas mensais externas dos dois períodos. No entanto, verifica-se que no verão, a tendência do usuário se encontrar em desconforto é maior do que no inverno. Quase que um terço dos pontos do gráfico de dispersão se encontra fora da zona de $80 \%$ dos usuários satisfeitos por zona de calor. Apesar de o período de inverno não apresentar muitas situações de desconforto térmico, quando o faz, a tendência é por zona de frio.

\section{Figura 2 - Condições de conforto térmico nos períodos de inverno e verão}

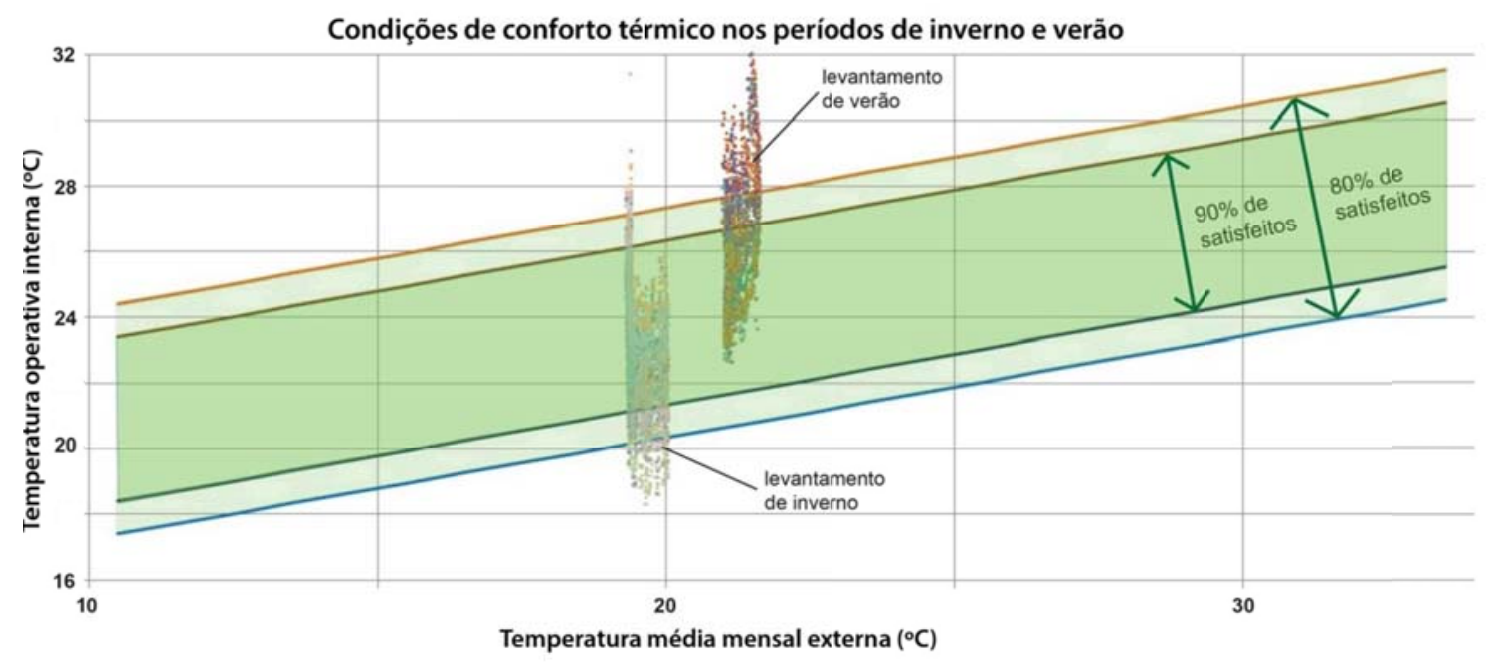

Fonte: autoria própria (2014)

Já analisando apenas as repostas dos questionários relacionados à percepção térmica, foi possível notar que a maioria dos voluntários idosos respondeu que não se encontravam nem com frio nem com calor, estando eles em conforto térmico. De todos os voluntários, apenas o da residência do Brooklin Novo respondeu que estava com calor e desconfortável nos dois períodos, sendo no de verão de grande intensidade. O voluntário do bairro do Rio Pequeno, apesar de ter respondido que estava com calor no período de inverno, disse que estava confortável com a situação. Dada as condições extremas e atípicas do período de verão de 2013 a 2014, é relevante apontar que as respostas obtidas relacionadas ao conforto térmico foram "confortável".

Assim, de acordo com o Quadro 1, apesar de ser uma pequena amostra, é possível notar certa tendência da não percepção do idoso frente situações de desconforto térmico causadas principalmente por calor. No instante o qual o questionário foi aplicado, anotaram-se as variáveis microclimáticas que o confortímetro apresentava. Assim, fezse a transformação delas para a aplicação no modelo adaptativo da norma e estabeleceram-se os cenários naquele exato momento. No período de verão, das seis residências apenas uma se encontrava em satisfação térmica (Aclimação - 90\% dos usuários satisfeitos por zona de calor). As cinco demais apresentavam situações de insatisfação térmica total por calor, sendo que as respostas obtidas pelos questionários eram de conforto térmico numa situação nem de frio nem de calor.

Dessa maneira, essa discordância entre as respostas dos usuários e os resultados da aplicação dos índices de conforto térmico pode reforçar a idéia de que diante das situações extremas de calor previstas a partir das mudanças climáticas, o corpo humano dos idosos pode entrar em um esforço fisiológico muito intenso, pela possibilidade de haver certa defasagem no tempo de resposta do processo termorregulatório. 
Quadro 1 - Tabulação das respostas dos questionários

\begin{tabular}{|c|c|c|c|c|c|c|c|c|c|c|c|c|c|}
\hline \multicolumn{2}{|c|}{ Questionário } & \multicolumn{2}{|c|}{ Vila Ida } & \multicolumn{2}{|c|}{ Aclimação } & \multicolumn{2}{|c|}{$\begin{array}{l}\text { Cerqueira } \\
\text { César }\end{array}$} & \multicolumn{2}{|c|}{$\begin{array}{l}\text { Freguesia } \\
\text { do Ó }\end{array}$} & \multicolumn{2}{|c|}{$\begin{array}{c}\text { Rio } \\
\text { Pequeno }\end{array}$} & \multicolumn{2}{|c|}{$\begin{array}{c}\text { Brooklyn } \\
\text { Novo }\end{array}$} \\
\hline 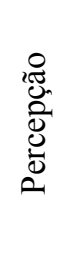 & $\begin{array}{l}\text { Muito frio } \\
\text { (MF), frio } \\
\text { (F), nenhum } \\
\text { (N), calor (C) } \\
\text { ou muito } \\
\text { calor (MC) }\end{array}$ & $\mathrm{N}$ & $\mathrm{N}$ & $\mathrm{N}$ & $\mathrm{N}$ & $\mathrm{N}$ & $\mathrm{N}$ & $\mathrm{N}$ & $\mathrm{N}$ & $\mathrm{C}$ & $\mathrm{N}$ & $\mathrm{MC}$ & $\mathrm{MC}$ \\
\hline $\begin{array}{l}\stackrel{0}{0} \\
\stackrel{0}{0} \\
0\end{array}$ & $\begin{array}{l}\text { Confortável } \\
\text { (C) ou } \\
\text { desconf. (D) }\end{array}$ & $\mathrm{C}$ & $\mathrm{C}$ & $\mathrm{C}$ & $\mathrm{C}$ & $\mathrm{C}$ & $\mathrm{C}$ & $\mathrm{C}$ & $\mathrm{C}$ & $\mathrm{C}$ & $\mathrm{C}$ & D & D \\
\hline \multicolumn{2}{|c|}{$\begin{array}{c}\text { Condição de } \\
\text { conforto pela } \\
\text { ASHRAE-55 } \\
90 \%, 80 \% \text { ou } \\
\text { insatisf. } \\
\text { Zona de calor (ZC)/ } \\
\text { de frio (ZF) }\end{array}$} & 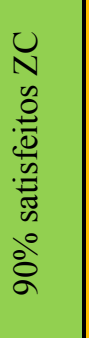 & 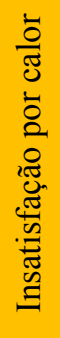 & 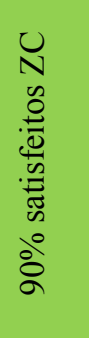 & 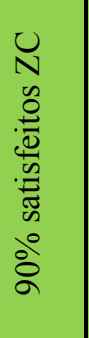 & 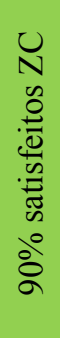 & 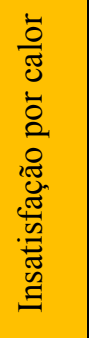 & 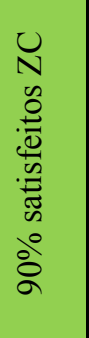 & 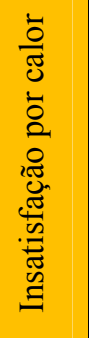 & 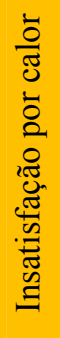 & 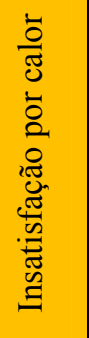 & 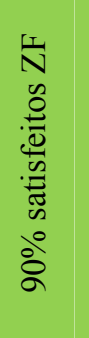 & 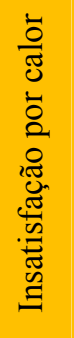 \\
\hline \multirow{3}{*}{ 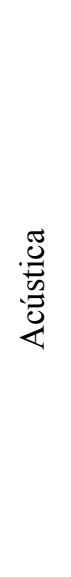 } & $\begin{array}{l}\text { Volume } \\
\text { ambiente - } \\
\text { percepção }\end{array}$ & 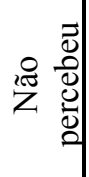 & $\begin{array}{l}\overline{\tilde{I}} \\
\text { Zे } \\
\text { z }\end{array}$ & $\begin{array}{l}\overline{\widetilde{Z}} \\
\text { Zे }\end{array}$ & 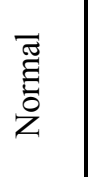 & 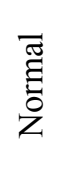 & $\begin{array}{l}\frac{0}{\pi} \\
\frac{1}{0} \\
0 \\
0 \\
0 \\
0\end{array}$ & $\begin{array}{l}\overline{\widetilde{E}} \\
\text { Zे }\end{array}$ & 敢 & $\begin{array}{l}0 \\
\frac{0}{\pi} \\
0 \\
0 \\
0 \\
0\end{array}$ & 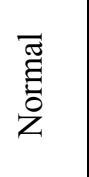 & . & $\begin{array}{l}\overline{\widetilde{\Xi}} \\
\text { है } \\
\text { Z }\end{array}$ \\
\hline & Qualificação & 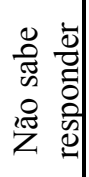 & 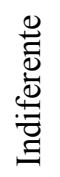 & 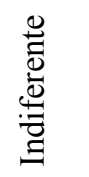 & 疋 & 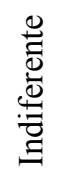 & 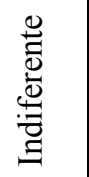 & 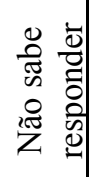 & 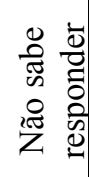 & 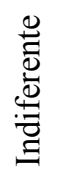 & 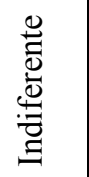 & 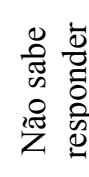 & 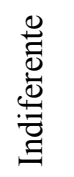 \\
\hline & Incômodo & $\begin{array}{l}\text { 言 } \\
\text { 节 } \\
\text { ż }\end{array}$ & $\begin{array}{l}\text { 竝 } \\
\text { 己े }\end{array}$ & $\begin{array}{l}\text { 音 } \\
\text { 离 } \\
\text { z }\end{array}$ & $\begin{array}{l}\stackrel{8}{\Xi} \\
\Xi \\
\Xi \\
\Xi\end{array}$ & $\begin{array}{l}\text { 竝 } \\
\text { ž }\end{array}$ & 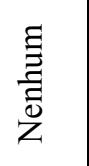 & 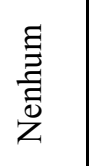 & $\begin{array}{l}\text { 音 } \\
\text { ż }\end{array}$ & 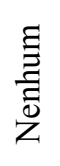 & $\begin{array}{l}\text { 离 } \\
\text { ż } \\
\text { ż }\end{array}$ & 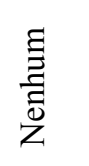 & $\begin{array}{l}\text { 离 } \\
\text { ż } \\
\text { ż }\end{array}$ \\
\hline \multirow{2}{*}{ 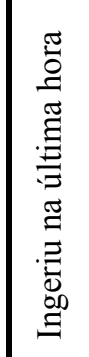 } & Alimentos? & $\begin{array}{l}\tilde{0} \\
\stackrel{0}{0} \\
\stackrel{\Xi}{\tilde{a}}\end{array}$ & $\stackrel{\mathbb{R}}{Z}$ & ही: & 胥 & $\frac{\infty}{\stackrel{\infty}{a}}$ & ही: & 胥 & 㞸 & Z & ही: & 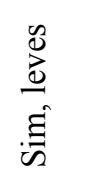 & $\stackrel{2 \pi}{2}$ \\
\hline & $\begin{array}{l}\text { Bebidas } \\
\text { alcoólicas? }\end{array}$ & 胥 & 胥 & Z & 胥 & Z & 胥 & 疍 & 倠 & 㞸 & 胥 & 胥 & 胥 \\
\hline
\end{tabular}

Fonte: autoria própria (2014). Cada residência possui duas colunas, sendo a da esquerda respostas referentes ao período de inverno e a da direita referentes ao período de verão.

Cabe ressaltar que muitos outros fatores influenciam nessa defasagem, como adiposidade, prática de esportes, uso de certos medicamentos, entre outros. É importante salientar que os questionários serviram para demonstrar a expressão do usuário idoso perante o próprio ambiente, sem, contudo apresentar a necessária relação entre o esforço fisiológico e a sensação experimentada no ambiente. 


\section{CONSIDERAÇÕES FINAIS}

A previsão tida atualmente é de que ocorram eventos climáticos ainda mais extensos e intensos, tendo um efeito do aumento da temperatura maior nos continentes do que nos oceanos, crescente da costa para o interior (OLIVEIRA, 2008). Ao mesmo tempo é estimado pelo Fundo de População das Nações Unidas (UNFPA) em seu relatório publicado em 2011, de que a tendência da população acima dos 60 anos é triplicar nos próximos 40 anos. Assim, é possível observar que durante os anos seguintes a tendência prevista consiste no agravamento das mudanças climáticas assim como no envelhecimento populacional.

Dessa maneira é necessário buscar meios e estratégias de resiliência das edificações, especialmente as da população idosa frente às condições climáticas cada vez mais agravantes. O objetivo fundamental de qualquer residência de qualquer indivíduo é servir como abrigo das condições externas. Assim, buscam-se internamente condições de conforto ambiental, especialmente o conforto térmico. (NICOL; HUMPHREYS; ROAF, 2012). Analisando a partir da perspectiva do modelo adaptativo, pode-se perceber que esta situação se adéqua bem à realidade brasileira, já que o modelo é direcionado a edificações condicionadas naturalmente, ou seja, de modo passivo.

É por essa razão que a presente pesquisa buscou um estudo de conforto térmico a partir de levantamentos empíricos. A partir da relação dos dados das variáveis microclimáticas com as respostas dos questionários, ou seja, do técnico-objetivo com o subjetivo, surgiram análises significantes de conforto térmico especialmente voltadas para a terceira idade, aspecto ainda não observado em território nacional.

Após a tabulação e o tratamento dos dados coletados em cada período, verificou-se a situação de conforto térmico presente em cada residência. A partir das respostas obtidas subjetivamente de cada idoso, confrontaram-se as duas situações. Verificou-se que a percepção do idoso perante a própria realidade térmica difere daquela tida a partir de modelos de conforto térmico adaptativo. Pelo fato da amostra ser reduzida e do caráter subjetivo dos questionários, não foi possível chegar a uma conclusão definitiva. No entanto, foi possível captar certos indícios que podem a vir expressar certa tendência. Essa tendência se refere ao fato de que os idosos não identificam situações de desconforto térmico, principalmente causado por calor e, portanto, encontram-se ainda mais vulneráveis ao estresse térmico devido ao aumento de temperatura. Assim, é de extrema importância atentar para esse público-alvo. Caberá a arquitetura contribuir no desenvolvimento de novas tecnologias habitacionais como meio de proteção do ambiente externo.

Apesar dos avanços na área científica brasileira de conforto térmico, é possível notar que não houve abordagens relativas à vulnerabilidade da população idosa. Dessa maneira, este trabalho serve como ponto de partida para que outras pesquisas possam explorar mais o tema e assim, contribuir ainda mais para a segurança dessa crescente parcela da sociedade diante das mudanças climáticas previstas.

\section{AGRADECIMENTOS}

À agência Fundação de Amparo à Pesquisa do Estado de São Paulo (FAPESP) pelo auxílio financeiro e aos pesquisadores do Laboratório de Conforto Ambiental e Eficiência Energética (LABAUT, FAUUSP) pelo apoio recebido. 


\section{REFERÊNCIAS}

AMERICAND SOCIETY OF HEATING, REFRIGERATING AND AIR CONDITIONING ENGINEERS (ASHRAE). ASHRAE 55-2010: Thermal Environmental Conditions for Human Occupancy. Atlanta: ASHRAE, 2010.

AUERBACH, P. S. Thermoregulation: Important modifications of thermoregulatory responses. In: Wilderness Medicine. 5th ed. Philadelphia: Mosby Elsevier, 2007.

FROTA, A. B., SCHIFFER, S. R. Manual de conforto térmico. 8 ed. São Paulo: Nobel, 2003.

GIVONI, Baruch. Passive and low energy cooling of buildings. John Wiley \& Sons, 1994.

INSTITUTO BRASILEIRO DE GEOGRAFIA E ESTATÍSTICA (IBGE). Censo 2010 resultado da amostra. Disponível em: $<$ http://www.censo2010.ibge.gov.br/apps/mapa/ $>$. Acesso em: 25 Jul. 2013.

INTERNATIONAL ORGANIZATION FOR STANDARDIZATION (ISO). ISO 10551, Subjective judgement scales. Genève: ISO, 1998b.

JENDRITZKY, G., DE DEAR, R. Adaptation and Thermal Environment. In: EBI, K. L. (ed), BURTON, I. (ed.), McGREGOR, G. (ed.). Biometeorology for Adaptation to Climate Variability and Change. Springer, 2009.

JOHN, V. M., SATO, N. M. N., AGROPYAN, V., SJOSTROM, C. Durabilidade e Sustentabilidade: Desafios para a Construção Civil Brasileira. Workshop sobre durabilidade das construções. São José dos Campos. 2001.

NICOL, J. F., HUMPHREYS, M., ROAF, S. Adaptive Thermal Comfort - principles and practice. Routledge, 2012.

NOBRE Carlos A. et al. Vulnerabilidade das Megacidades Brasileiras às Mudanças climáticas: Região metropolitana de São Paulo. Sumário executivo. 2010.

MONTEIRO, L. M., ALUCCI M. P. Comparação cruzada entre pesquisas laboratoriais e de campo em conforto térmico em espaços abertos urbanos. Faculdade de Arquitetura e Urbanismo, Universidade de São Paulo, São Paulo, 2010.

MONTEIRO, L. M. Modelos preditivos de conforto térmico: quantificação de relações entre variáveis microclimáticas e de sensação térmica para avaliação e projeto de espaços abertos. Tese de doutorado. Faculdade de Arquitetura e Urbanismo, Universidade de São Paulo, SP, 2008.

OLIVEIRA, S. M. B. Base científica para a compreensão do aquecimento global. In: VEIGA, José Eli da (org). Aquecimento Global: frias contendas científicas. São Paulo: Editora Senac São Paulo, 2008.

PEREIRA, C. D., GHISI, E. The influence of the envelope on the thermal performance of ventilated and occupied houses. Energy and Buildings, v. 12, n. 43, p. 3391-3399, 2011.

UNITED NATIONS ENVIRONMENT PROGRAMME (UNEP). Buildings and Climate Change: Status, challenges and opportunities. 2007. Disponível em: <http://www.unep.org/sbci/pdfs/BuildingsandClimateChange.pdf >. Acesso em: 20 nov. 2012.

UNITED NATIONS HUMAN SETTLEMENTS PROGRAMME (UN-HABITAT). Cities and

climate change: global report on human settlements. 2011. Disponível em: $<$ http://www.unhabitat.org.jo/en/inp/Upload/2332420_GRHS-2011.pdf $>$. Acesso em: 30 nov. 2012.

UNITED NATIONS POPULATION FUND (UNFPA). State of World Population 2011 People and Possibilities in a World of 7 Billion. 2011. Disponível em: $<$ http://www.unfpa.org/public/home/publications/pid/8726>. Acesso em 15 fev. 2014. 